\title{
Features of the economical yield formation of apple plants under non-root nutrition in the Southern Russia organic plantings
}

\author{
Tatiana Doroshenko ${ }^{1 *}$, Lyudmila Ryazanova ${ }^{1}$, Galina Petrik ${ }^{1}$, Igor Gorbunov ${ }^{1}$, and \\ Sergey Chumakov ${ }^{1}$ \\ ${ }^{1}$ Kuban State Agrarian University, Kalinina str., 13, Krasnodar, 350044, Russia
}

\begin{abstract}
In this work are determined the prospects of application new complex fertilizer chelate "Naliv" for apple plants non-root nutrition in connection with optimization of economic yield formation in the Southern Russia organic plantations. The field experiment was carried out in the organic apple tree plantations of the educational farm "Kuban" of the KubSAU, planted in 2002. The experimental field soil is leached chernozem. Trees foliar dressing was carried out with organic fertilizer 40-45 days before harvest. Control variant was trees treatment with water. The accumulation of glucose and fructose, associated with a significant (1.4 times) increase in their average weight, activate in ripening fruits under fertilizer application as a late-summer foliar dressing. Equally, the economic yield increases by $14 \%$ compared to control value. The fertilizer application accelerates the generative apple bud dormancy beginning and, accordingly, dormancy ending. An increase in the abscisic acid content in generative buds in late autumn, initiated by the fertilizer action, plays a certain role in achieving this effect. Equally, the plants resistance to low temperatures of the spring increases. Thus, favorable conditions are created to improve the commercial quality of fruits and optimize fruiting in adjacent years under fertilizers application in organic apple plantations.
\end{abstract}

\section{Introduction}

Organic gardening is one of the priority directions of the agro-industrial complex development, providing the production of ecologically clean fruit products $[1,2]$. Significant interest in this market segment is associated with the aspirations of the population to a sustainable increase in the standard of living, the main condition of which is a healthy diet [3]. At the same time, the fundamental role of fruits and berries as a source of most vitamins and other biologically active substances is taken into account [4, $5]$.

By now a set of technological elements has already been developed that ensure an increase in plant productivity, as well as the implementation of mechanisms for selfregulation of plant organisms in artificially created ecosystems of organic perennial

* Corresponding author: doroshenko-t.n@yandex.ru 
plantings while preserving the natural basis [6-9]. In particular, the principles of selecting the best pomological varieties of a certain breed are formulated, taking into account the degree of compliance in the "genotype-environment" system, which ensures the sustainable functioning of the orchard ecosystem. The biological and production characteristics of the assortment (varieties and rootstocks) of apple trees, promising for use in organic plantations, are given [9]. The practicability of applying the program of ecological management of populations of harmful and useful species, which allows to significantly reduce the number of treatments against apple pests with biological agents, is also shown $[3,10]$.

To a lesser extent, the scientific literature highlights the results of studies on the particularities of root nutrition of fruit plants in organic plantations. It is only known that the highest fruit yield in a non-irrigated organic apple orchard is achieved by using skiprow grassing-down of spacing by naturally growing grasses of a certain species composition [9]. Obviously, the use of this method of soil management in plantings of the southern region of Russia, which involves enriching the soil with organic matter due to the decomposition of the mowed mass of perennial grasses, eliminates the need for organic fertilizers, providing, moreover, optimization of the main parameters of the fertility of leached chernozem. At the same time, there is practically no information concerning the prospects of application non-root plant nutrition in organic orchards, which is an important technique for the directed regulation of their growth and development $[1,11-15]$. In this regard, the purpose of these studies was to determine the action spectrum of a new fertilizer for non-root nutrition of apple plants in connection with the optimization of the formation of the economic harvest in organic plantations in the southern Russia in adjacent years.

\section{Materials and Methods}

The research was carried out in 2019-2021 in the conditions of field and laboratory experiments. The field experiment was carried out in the organic apple tree plantations of the educational farm "Kuban" of the Kuban State Agrarian University, laid in 2002 (Krasnodar: $45^{\circ} 02^{\prime} \mathrm{N}, 38^{\circ} 59^{\prime} \mathrm{E}$ ). The trees are placed according to the scheme $5 \times 3 \mathrm{~m}$. The soil of the experimental field is leached chernozem (the content of total humus is $3.8 \%$ ). The method of spacing soil management is skip-row grassing-down by naturally growing groundcover grasses [9]. The promising for growing in organic apple plantations in the southern Russia Florina variety, grafted on the MM106 rootstock, was studied. The experiment provided for two variants:

1. Control (treatment of trees with water).

2. Trees foliar dressing with a new generation organic fertilizer chelate "Naliv", allowed for application in organic farming (the recommended consumption norm is 0.5 $1 /$ ha; the application period is $40-45$ days before fruit harvest).

Chelate "Naliv" is a complex organic fertilizer obtained by accelerated fermentation of horse manure. It contains humic and fulvic acids, amino acids, including proline, as well as various nutrients.

The agricultural technology at the experimental field met the requirements set out in the Russian regional recommendations.

The number of replications of the experiment is five. A "tree-plot" is accepted as a one replication.

Records and observations in the orchard, as well as the assessment of the biological parameters of apple plants (including the stages of organogenesis) were carried out by generally accepted methods [11]. The method of capillary electrophoresis was used to determine the content of growth regulators in the apical buds of annual shoots and the 
concentration of carbohydrates in the leaves. The number of replications of laboratory experiments is two. The analysis of the obtained results was carried out using the methods of mathematical statistics.

\section{Results and Discussion}

As the experiment showed, the content of monosaccharides increases in the leaves of apple trees, but the concentration of sucrose significantly decreases under the influence of the organic fertilizer chelate "Naliv" (Table 1). At the same time, a sharp increase in these indicators was recorded in ripening fruits. The content of monosaccharides in them under application of foliar dressing is in 1.8 times more than in the control variant, and sucrose - $10 \%$ more.

Table 1. The effect of foliar dressing with organic fertilizer on the content of mono - and oligosaccharides in the leaves and fruits of apple trees of the Florina variety, $\mathrm{mg} / \mathrm{g}$ of dry matter

(28.08.2020)

\begin{tabular}{|c|c|c|c|c|}
\hline \multirow{2}{*}{ Variant } & \multicolumn{2}{|c|}{ Leaves } & \multicolumn{2}{c|}{ Fruits } \\
\cline { 2 - 5 } & $\begin{array}{c}\text { Glucose }+ \\
\text { fructose }\end{array}$ & Sucrose & $\begin{array}{c}\text { Glucose }+ \\
\text { fructose }\end{array}$ & Sucrose \\
\hline $\begin{array}{c}\text { Control } \\
\text { (water } \\
\text { treatment) }\end{array}$ & $3.07 \pm 0.14$ & $3.37 \pm 0.25$ & $57.52 \pm 6.9$ & $13.85 \pm 0.48$ \\
\hline $\begin{array}{c}\text { Chelate } \\
\text { "Naliv" }\end{array}$ & $3.51 \pm .014$ & $2.66 \pm 0.25$ & $105.26 \pm 6.9$ & $15.22 \pm 0.48$ \\
\hline
\end{tabular}

Based on the obtained data, it can be claimed that:

- the intensity of biosynthesis of monosaccharides (glucose and fructose) in the leaves of apple trees increase under the influence of non-root nutrition with the fertilizer chelate "Naliv";

- $\quad$ at the same time, the activity of transportation from the leaves to the ripening fruits of sucrose oligosaccharide (the main transport form of sugars in the plant) and its further conversion into glucose and fructose increases;

- $\quad$ activation of the accumulation of simple sugars in apple fruits, induced by the action of fertilizer, is associated with a significant increase in their average weight in comparison with the control variant. According to the results of the records carried out in 2019 , this parameter in the variant with the fertilizer application reached $142.5 \mathrm{~g}$, while in the control variant it was only $95 \mathrm{~g}\left(\mathrm{LCD}_{0.5}=11.1 \mathrm{~g}\right)$. In 2020 , the average weight of fruits in the experimental variant was 1.3 times higher than the control value.

Thus, the application of non-root fertilizer chelate "Naliv" in the second half of the plant growing season provides an increase in the commercial quality of apple fruits produced using organic technology. It is noteworthy that under the influence of this method, the economic yield of apple trees increases in comparison with the control by only $14 \%$ (Table 2). Obviously, such a noticeable increase in the fruit quality does not lead to an adequate increase in their quantity. Probably, the reason for this discrepancy, associated with an increase in the pre-harvest ovaries drop, is an excessively large number of consumers of assimilates - ripening fruits, which goes beyond the capabilities of the plant organism in the synthesis of assimilates. 
Table 2. The effect of foliar dressing with organic fertilizer on the peculiarities of the formation of the apple fruit yield of the Florina variety in the adjacent years (2020 - 2021)

\begin{tabular}{|c|c|c|c|c|c|c|c|}
\hline \multirow[t]{2}{*}{ Variant } & $\begin{array}{l}\text { Econo } \\
\text { mic } \\
\text { vield. }\end{array}$ & $\begin{array}{c}\text { The } \\
\text { set of } \\
\text { genera } \\
\text { tive }\end{array}$ & \multicolumn{4}{|c|}{ Stages of organogenesis } & \multirow{2}{*}{$\begin{array}{c}\text { Number } \\
\text { of } \\
\text { infloresc } \\
\text { ences, } \\
\text { pcs/ } \\
\text { tree } \\
10.05 . \\
2021\end{array}$} \\
\hline & $\begin{array}{c}18.09 . \\
2020\end{array}$ & $\begin{array}{c}19.11 . \\
2020\end{array}$ & $\begin{array}{c}19.11 . \\
2020\end{array}$ & $\begin{array}{c}27.01 . \\
2021\end{array}$ & $\begin{array}{c}01.03 . \\
2021\end{array}$ & $\begin{array}{c}29.03 . \\
2021\end{array}$ & \\
\hline $\begin{array}{l}\text { Control } \\
\text { (water } \\
\text { treatment) }\end{array}$ & 30.8 & 46 & III & IV & IV & V & 136 \\
\hline $\begin{array}{l}\text { Chelate } \\
\text { "Naliv" }\end{array}$ & 35.1 & 43 & IV & IV & V & VII & 160 \\
\hline $\operatorname{LCD}_{0,5}$ & 3.8 & - & - & - & - & - & 12 \\
\hline
\end{tabular}

A significant part of the photosynthetic products in the second half of the summer period is involved in the processes of set and development of generative apple buds, which determine the size of the next season's fruit yield. According to our data, the application of the fertilizer chelate "Naliv" along with the active accumulation of sugars in the ripening fruits provides a fairly intensive (as well as in the control) setting of generative buds. At the same time, the setting of flower buds and the beginning of their differentiation in apple plants in the variant with application of fertilizer is shifted to earlier terms.

This statement is supported by the differences noted already at the end of autumn between the variants in the content of phytohormones in the apical buds of annual shoots: an increase of $36 \%$ in comparison with the control concentration of abscisic acid (ABA) and a simultaneous decrease in the content of indolylacetic acid in them. These differences indicate an earlier weakening of growth activity and, accordingly, an increase in generative activity in apple plants that received non-root fertilizer chelate "Naliv". On the other hand, under application of fertilizer in the second half of the summer season, apple plants in the early spring of the following year recorded an acceleration of the passage of the V-VII stages of organogenesis, corresponding to the formation of flower organs, as well as male and female gametophytes [11].

With such an acceleration of the generative development of a plant organism against the background of "jumps" in the average daily air temperature, which rises during March to the level of $10.1{ }^{\circ} \mathrm{C}$ and decreases to $-4.6^{\circ} \mathrm{C}$, it is logical to expect significant damage to flower buds caused by the action of a temperature stressor. However, contrary to the forecast, the number of inflorescences on apple trees in the variant with the application of fertilizer in the "mass flowering" phase is $18 \%$ more than in the control variant. Probably, the timing of the plant organism dormancy end is not the only criterion for its resistance to low spring temperatures. It is appropriate to note that an important component of the organic fertilizer chelate "Naliv" is the amino acid proline, which is usually considered as a cryoprotective substance that performs a protective function. Based on the presented materials, the organization at the end of the summer period of foliar dressing of apple plants with organic fertilizer chelate "Naliv" increases their resistance to low temperatures. A certain role in the realization of this trait of an increase 
in the content of $\mathrm{ABA}$ in the plant generative buds caused by the action of fertilizer is not excluded.

The possibility of regulating the development of generative apple buds with the application of some new generation biologically active substances of was shown earlier [11]. A similar effect was obtained in the case of the application of the fertilizer chelate "Naliv". Obviously, in the production of ecologically clean products in apple plantations in the southern Russia, it is very promising to use late-summer complex organic fertilizer chelate "Naliv", which provides an increase in the commercial quality of fruits and optimization of fruiting in adjacent years, even against the background of weather stress factors.

\section{Conclusion}

The data indicating a wide range of effects on the plant organism of the complex organic fertilizer chelate "Naliv" were obtained. Against the background of its application in organic plantings of apple trees in the southern Russia, the accumulation of monosaccharides (glucose and fructose) is activated in the ripening fruits, which is associated with a significant (1.4 times) increase in their average weight. At the same time, the economic yield increases by $14 \%$ compared to the control value. The application of the fertilizer chelate "Naliv" accelerates the generative apple bud dormancy beginning and, accordingly, dormancy ending. A certain role in achieving this effect is played by an increase in the content of ABA in plant generative buds initiated by the action of fertilizer in late autumn terms. At the same time, the plant resistance to low temperatures of the spring period increases. Thus, against the background of foliar dressing with complex fertilizer in organic apple plantations, favorable conditions are created to improve the commercial quality of fruits and optimize fruiting in adjacent years.

Acknowledgments. The reported study was funded by RFBR and Krasnodar Territory Administration according to the research project No. 19-44-230013r_a.

\section{References}

1. S. De Pascale, Y. Rouphael, G. Colla, Eur. J. Hortic. Sci., 82, 277-285 (2017) http://doi.org/10.17660/eJHS.2017/82.6.2

2. T. de Ponti, B. Rijk, and M. K. van Ittersum, Agric. Syst., 108, 1-9 (2012) http://doi.org/10.1016/j.agsy.2011.12.004

3. H. Willer, J. Lernoud, L. Kemper, FiBL \& IFOAM - Organics International, 354 (2018) https://orgprints.org/id/eprint/34669/1/WILLER-LERNOUD-2018-finalPDF-low.pdf

4. M. Bassi, G. Lubes, F. Bianchi, S. Agnolet F. Ciesa, K. Brunner, W. Guerra, P. Robatscher, M. Oberhuber, Int. J. Food Prop., 20, S2626-S2634 (2018) http://doi.org/10.1080/10942912.2017.1381705

5. L.V. Donchenko, T.N. Doroshenko, E.A. Krasnoselova, E.V. Konuhova, G.F. Petrik, IOP Conf. Series: Earth Env. Scie., 488, 012008 (2020) http://doi.org/10.1088/17551315/488/1/012008

6. B. Scaglia, R.R. Nunes, M.O.O. Rezende, F. Tambone, F. Adani, Sci. Total Environ., 562, 289-295 (2016) https://doi.org/10.1016/j.scitotenv.2016.03.212

7. M. Ruzzi, R. Aroca, Sci. Hortic., 196, 124-134

https://doi.org/10.1016/j.scienta.2015.08.042 
8. T. Frioni, P. Sabbatini, S. Tombesi, J. Norrie, S. Poni, M. Gatti, A. Palliotti, Sci. Hortic., 232, 97-106. (2018) https://doi.org/10.1016/j.scienta.2017.12.054

9. T.N. Doroshenko, G.F. Petrik, S.S. Chumakov, S.B. Krivorotov, A.P. Maksimenko, J. Pharm. Sci. Res., 7, 1652-1655 (2018) https://www.scopus.com/record/display.uri?eid=2-s2.085051072886\&origin $=$ resultslist

10. E.S. Sugonyaev, I.V. Balakhnina, T.N. Doroshenko, V.A. Yakovuk, O.S. Shevchenko, L.A. Vasilyeva, I.N. Pastarnak, Ent. Review, 8, 1075-1090 (2014) https://doi.org/10.1134/S0013873814080041

11. T.N. Doroshenko, S.S. Chumakov, D.V. Maksimtsov, B.S. Gegechkori, S.S. Chukuridi, Int. J. Green Pharm., 3, 160-165 (2017) https://www.scopus.com/record/display.uri?eid=2-s2.085034955243\&origin=resultslist

12. M.M. Blanke, A. Kunz, Sci. Hortic., 198, 434-437 https://doi.org/10.1016/j.scienta.2015.12.019

13. G. Colla, Y. Rouphael, Sci. Hortic., 196, 1-2 (2015) https://doi.org/10.3389/fpls.2020.00040

14. E. Aglar, K. Yildiz, Y. Ozkan, B. Ozturk, H. Erdem, Sci. Hortic., 213, 173-178 (2016) https://doi.org/10.1016/j.scienta.2016.10.026

15. T.N. Doroshenko, G.F. Petrik, L.G. Ryazanova, S.S. Chumakov, N.V. Matuzok, Agri Bio Research Publishers, 25(2), 302-307 (2020) https://www.scopus.com/record/display.uri?eid=2-s2.0$\underline{85091939498 \& \text { origin }=\text { resultslist }}$ 